\title{
Renal changes in long-term Type 1 (insulin-dependent) diabetic patients with and without clinical nephropathy: a light microscopic, morphometric study of autopsy material
}

\author{
O. Frøkjær Thomsen ${ }^{2}$, A. R. Andersen ${ }^{1}$, J.Sandahl Christiansen ${ }^{1}$ and T. Deckert ${ }^{1}$ \\ ${ }^{1}$ Steno Memorial Hospital, Gentofte and ${ }^{2}$ Department of Pathology, Rigshopitalet, Copenhagen, Denmark
}

\begin{abstract}
Summary. The relationship between clinical diabetic nephropathy and morphological renal changes was studied in autopsy material from 34 long-term Type 1 (insulin-dependent) diabetic patients of juvenile onset. Seventeen had no clinical signs of nephropathy (defined by persistent proteinuria, hypertension, and elevated serum creatinine) while a further 17 age-matched diabetic patients with a similar duration of diabetes had severe clinical nephropathy. The renal tissue was examined by morphometric light microscopy, using a point counting technique and the results compared with renal tissue from subjects who died without diabetes. In the diabetic patients without clinical nephropathy, arteriolohyalinosis was much more pronounced compared with non-diabetic subjects $(2 p<0.001)$ and within the glomeruli the amount of subcapsular fibrosis and glomerular mesangium was increased $(2 p<0.05$ and $<$ 0.001 , respectively). The area of open capillaries was decreased compared with non-diabetic subjects $(2 p<0.025)$, and the percentage of occluded glomeruli was significantly increased $(2 p<0.05)$. The diabetic patients with clinical nephropathy had significantly more interstitial tissue and glomerular mesangium $(2 p<0.001)$ and less open glomerular capillaries $(2 p<0.001)$ than diabetic subjects without clinical
\end{abstract}

nephropathy, but severe glomerulosclerosis could be seen in the diabetic patients without any sign of clinical nephropathy. Serum creatinine correlated with the mesangial area $(r=0.792,2 \alpha<0.001)$. No difference was observed between the two diabetic groups regarding the degree of arteriolohyalinosis, the number of Kimmelstiel-Wilson lesions or exudative lesions. A significant negative correlation existed between the relative area of open capillaries and the relative area of mesangium ( $r=-0.86,2 \alpha<0.001)$. Remarkable mesangial enhancement was present in most of the diabetic patients with, but also in several diabetic subjects without, clinical nephropathy. On the other hand, the area of open capillaries was within the normal range in most of the patients who did not show any clinical sign of nephropathy. Thus, preservation of a normal area of open capillaries in renal tissue from long-term diabetic patients with glomerulosclerosis seems to be a good light microscopic indicator of absence of clinical nephropathy.

Key words: Glomerulosclerosis, nephropathy, Type 1 diabetes, arteriolohyalinosis, Kimmelstiel-Wilson nodules, mesangium, open capillaries.
Ten years after the onset of diabetes, morphological kidney changes are seen by light microscopy in nearly all Type 1 (insulin-dependent) diabetic patients of juvenile onset $[1,4]$. These changes comprise diffuse or nodular glomerulosclerosis, exudative lesions in the glomeruli, arteriolar changes, and tubular lesions with atrophy and basement membrane thickening.

In general, the morphological renal changes are considered to correspond grossly with the severity of clinical symptoms and signs. However, perusal of autopsy and biopsy reports showed that both diffuse and nodular glomerulosclerosis of moderate and even severe degrees have been described in patients who had never suffered from clinical diabetic nephropathy [1-5]. This discrepancy between morphological and clinical features raises the question whether autopsy material of renal tissue - with all the heterogenous renal changes found at the terminal stage of disease - can indeed re- veal specific changes which can be correlated with the presence or absence of clinical diabetic nephropathy.

As there is little evidence on this point, we investigated kidney tissue taken at autopsy from Type 1 diabetic patients with either severe clinical nephropathy or with no clinical signs of nephropathy.

\section{Subjects and methods}

\section{Subjects}

Among Type 1 diabetic patients in whom an autopsy had been performed and paraffin blocks with kidney material were available, we selected 17 pairs of age- and sex-matched patients with similar duration of diabetes with and without clinical nephropathy. The onset of diabetes was before the age of 31 years, and the patients were followed for many years at the Steno Memorial Hospital. Cases with a history of non-diabetic renal or post-renal diseases were excluded. In 24 of the 34 patients (12 in each group) bacterial culture of the urine had been performed. All cultures were negative. The remaining 
Table 1. Clinical data of Type 1 diabetic patients with and without diabetic nephropathy and non-diabetic subjects

\begin{tabular}{|c|c|c|c|c|c|}
\hline & \multirow{2}{*}{$\begin{array}{l}\text { Age } \\
\text { (years) }\end{array}$} & \multirow{2}{*}{$\begin{array}{l}\text { Duration } \\
\text { of diabetes } \\
\text { (years) }\end{array}$} & \multicolumn{2}{|c|}{ Blood pressure $(\mathrm{mmHg})$} & \multirow{2}{*}{$\begin{array}{l}\text { Serum creatinine } \\
(\mu \mathrm{mol} / 1)\end{array}$} \\
\hline & & & systolic & diastolic & \\
\hline No clinical nephropathy $(n=17)$ & $50 \pm 2.3$ & $29 \pm 2.2$ & $130 \pm 9$ & $80 \pm 4$ & $87 \pm 5$ \\
\hline Non-diabetic subjects $(n=10)$ & $50 \pm 15$ & 0 & $128 \pm 28$ & $79 \pm 13$ & $87 \pm 19$ \\
\hline
\end{tabular}

Results are expressed as mean $\pm \mathrm{SD}$

10 patients had normal urine microscopy. Our criteria for the presence of severe diabetic nephropathy were the following: (1) persistent proteinuria (>0.5 g protein. $\left.1^{-1} \cdot 24 \mathrm{~h}^{-1}\right)$ for several years, (2) hypcrtension (>140/90 mmHg), and (3) elevated serum creatinine. Our criteria for the absence of clinical nephropathy were: (1) normal serum creatinine levels, (2) no hypertension (i.e. blood pressure $<$ $140 / 90 \mathrm{mmHg}$ ), and (3) several negative tests of 24-h urine-samples with Albustix (sensitivity $200-300 \mathrm{mg}$ protein/1 urine) during the last year before death.

Seventeen patients died from clinical diabetic nephropathy after 3-20 years of proteinuria (mean 9.7 years). All patients showed urinary protein excretion $>1.0 \mathrm{~g} / 24 \mathrm{~h}$, elevated serum creatinine $>$ $200 \mu \mathrm{mol} / 1$ and elevated blood pressure ( $\geqq 90 \mathrm{mmHg}$ diastolic), except one patient who died in septic shock. The causes of death in this group were uraemia (14), pulmonary embolism (one), pulmonary oedema (one), and peritonitis (one). Dialysis or transplantation was not offered to these patients for various reasons. Seventeen other patients died without clinical signs of diabetic nephropathy. The causes of death were coronary infarction (nine), pneumonia (three), hypoglycaemia (one), ketoacidosis (one), cerebrovascular accident (one), pulmonary embolism (one), and unknown (one).

Ten subjects of comparable age without diabetes or renal disease served as controls. The causes of death among these patients was metastatic cancer (four), cerebral haemorrhage (four), and myocardial infarction (two). The clinical data of patients and control subjects are shown in Table 1.

\section{Methods}

Autopsy was performed in the usual way. The weight of the kidney was not determined, but in every case it was stated that the kidney was macroscopically normal or large. Formalin-fixed, paraffin-embedded kidney tissue, sampled at the autopsy, was used. From each block of tissue, three sections $(4 \mu \mathrm{m})$ were cut and stained with (respectively) haematoxylin-eosin, periodic acid-Schiff, and Picro-Sirius (a modification of van Gieson stain, using Sirius-red instead of fuchsin).

In the sections of kidney tissue, a rectangular cortical area, $2.5 \mathrm{~mm}$ in breadth and $5 \mathrm{~mm}$ in depth, situated along a line at the middle of, and at right angles to the cortical surface, was studied. The following measurements were made: (1) the total number of glomeruli, with registration of the number of totally occluded glomeruli; (2) the number of glomeruli with Kimmelstiel-Wilson lesions and/or capsular drops; (3) the number of juxtaglomerular (afferent or efferent) arterioles, and the degree of hyalinosis graded I-IV according to Bader and Meyer [7] registered; (4) by using an ocular grid containing 36 points at $\times$ 100 magnification, the number of points coinciding with glomeruli, vessels, interstitium, and tubules were counted. From these data, the percentage distribution of these structures was calculated. Additionally every glomerulus in the investigated rectangular area was examined by point-counting technique, using the 36-point grid at $\times 400$ magnification. The number of points coinciding with the following structures were counted: the capsule of Bowmann; capsular space; epithelial cells; free capillary wall; capillary lumen; mesangium; subcapsular fibrosis; fibrinoid caps; hilus region; and "undeterminable'. By addition of the numbers of points for each structure, the percentage distribution of the structures in the investigated area could be calculated for each individual.

The renal tissue from the diabetic patients was examined without knowledge of which group the patient belonged to.

\section{Statistical analysis}

The Mann-Whitney test and Student's t-test were used for statistical evaluation. Linear regression and correlation coefficient were calculated according to standard methods. Results are expressed as mean $\pm \mathrm{SD}$.

\section{Results}

The patients with clinical diabetic nephropathy had significantly more glomeruli, including sclerotic ones, than the diabetics without clinical nephropathy $(2 p<0.001$; Table 2). The number of glomeruli was not significantly higher in patients without clinical nephropathy than in the non-diabetic subjects $(2 p>0.05)$. The percentage of occluded glomeruli was significantly higher in patients with severe clinical nephropathy than in patients without clinical nephropathy $(2 p<0.001)$, and higher in the latter group compared with non-diabetic subjects $(2 p<0.02)$.

The number of glomeruli showing Kimmelstiel-Wilson lesions was not greater in the diabetic patients who died with severe clinical nephropathy than in patients with comparable duration of diabetes, but dying without clinical signs of nephropathy. Non-diabetics had no glomeruli with the Kimmelstiel-Wilson lesion. No difference was found between the number of capsular drops among the two diabetic groups. Only one capsular drop was seen among the 313 glomeruli of the nondiabetic subjects.

Between three and 17 juxtaglomerular arterioles (mean nine) were seen and evaluated in every case (Table 3). Arteriolohyalinosis in the non-diabetic subjects was rare, and the degree not pronounced. The relative numbers of hyalinized arterioles (grade I-III) were about the same in the two diabetic groups. A slightly higher number of severely hyalinized arterioles (grade IV) was seen in patients with clinical nephropathy than in patients without nephropathy. The difference however was not significant $(2 p>0.05)$. Table 4 shows the relative distribution of the four main types of renal structures in the area examined. The area of interstitial tissue was significantly greater in patients with nephropathy than in patients without nephropathy $(2 p<$ 0.001 ); complementary to this the area of tubules was less $(2 p<0.001)$, indicating an increase of connective tissue (fibrosis) in patients with severe clinical nephropathy. A negative correlation was demonstrated in the whole material between the area of interstitial tissue 
Table 2. Number of glomeruli, sclerotic glomeruli, glomeruli with Kimmelstiel-Wilson noduli and capsular drops in the patients studied

\begin{tabular}{|c|c|c|c|c|}
\hline & $\begin{array}{l}\text { Number of } \\
\text { glomeruli }\end{array}$ & $\begin{array}{l}\text { Mean number } \\
\text { of sclerotic } \\
\text { glomeruli }\end{array}$ & $\begin{array}{l}\text { Mean number of } \\
\text { glomeruli with } \\
\text { Kimmelstiel- } \\
\text { Wilson lesion }\end{array}$ & $\begin{array}{l}\text { Mean number of } \\
\text { glomeruli with } \\
\text { capsular drop }\end{array}$ \\
\hline $\begin{array}{l}\text { No clinical nephropathy } \\
\quad(n=17)\end{array}$ & $\begin{array}{l}34.7 \pm 10.6^{\mathrm{a}} \\
(22-63)\end{array}$ & $\begin{array}{l}6.5^{\mathrm{a}} \\
(0-24)\end{array}$ & $\begin{array}{l}2.2 \\
(0-18)\end{array}$ & $\begin{array}{c}0.3 \\
(0-2)\end{array}$ \\
\hline $\begin{array}{l}\text { Severe clinical nephropathy } \\
\quad(n=17)\end{array}$ & $\begin{array}{l}43.9 \pm 9.5^{\mathrm{a}} \\
(30-66)\end{array}$ & $\begin{array}{l}21.6^{\mathrm{a}} \\
(6-40)\end{array}$ & $\begin{array}{l}3.4 \\
(0-20)\end{array}$ & $\begin{array}{c}0.5 \\
(0-4)\end{array}$ \\
\hline $\begin{array}{l}\text { Non-diabetic subjects } \\
\quad(n=10)\end{array}$ & $\begin{array}{l}31.3 \pm 10.3 \\
(18-49)\end{array}$ & $\begin{array}{c}0.4 \\
(0-3)\end{array}$ & $\begin{array}{l}0.0 \\
(0)\end{array}$ & $\begin{array}{c}0.1 \\
(0-1)\end{array}$ \\
\hline
\end{tabular}

Results are expressed as mean $\pm \mathrm{SD}$ (ranges in parentheses). a $2 p<0.01$

Table 3. Degree of arteriolohyalinosis in diabetic patients without and with clinical nephropathy and non-diabetic subjects

\begin{tabular}{lllllll}
\hline & $\begin{array}{l}\text { Total number of } \\
\text { juxtaglomerular } \\
\text { arterioles }\end{array}$ & \multicolumn{4}{c}{ Degree of hyalinosis (\%) } \\
\cline { 3 - 7 } & 178 & I & II & III & IV \\
\hline $\begin{array}{c}\text { No clinical } \\
\text { nephropathy }\end{array}$ & 145 & 28.1 & 35.4 & 24.1 & 12.4 \\
$\begin{array}{c}\text { Severe clinical } \\
\text { nephropathy }\end{array}$ & 87 & 22.8 & 35.2 & 21.4 & 20.7 \\
$\begin{array}{c}\text { Non-diabetic } \\
\text { subjects }\end{array}$ & 91.6 & 5.3 & 3.1 & 0 \\
\hline
\end{tabular}

The degree of hyalinosis was expressed after Bader and Meyer [7]: $\mathrm{I}=$ no conspicuous alteration of arteriolar wall; $\mathrm{II}=$ arteriolar wall hyalinosis comprising $<50 \%$ of arteriolar circumference; $\mathrm{III}=$ arteriolar wall haylinosis comprising $>50 \%$, but not the whole of arteriolar circumference; $I V=$ hyalinization and thickening of the whole arteriolar wall with severe narrowing of the arteriolar lumen.

The difference of severe arteriolohyalinosis (grade III + IV) between the diabetic groups was not significant, whereas the difference between non-diabetic patients and patients without nephropathy was highly significant $\left(2 p<0.001 ; \chi^{2}\right.$-test $)$

and the area occupied by tubuli $(r=-0.932,2 \alpha<$ 0.001 ), indicating a close interdependence of these two structures. No difference was observed between the areas occupied by blood vessels or glomeruli. Considering that the number of glomeruli was highest in patients with nephropathy (Table 2), the size of these glomeruli must be reduced, probably because of the higher number of sclerosed glomeruli in these patients. The increased number of glomeruli was probably due to the process of fibrosis with shrinkage of the cortical layer of the kidney.

The relative distribution of intraglomerular structures is given in Table 5. The non-diabetic patients had significantly less mesangial tissue and subcapsular fibrosis compared with the diabetic patients with $(2 p<$ 0.001 for each) and without nephropathy $(2 p<0.001$ and $<0.05$ respectively). The area of open capillaries (defined as capillary lumen plus peripheral capillary wall) was higher than in the two diabetic groups $(2 p<$ $0.001)$.

Within the diabetic groups, the areas of mesangium and subcapsular fibrosis (seen mainly in the sclerotic glomeruli) was higher in patients with clinical nephrop-
Table 4. Distribution of the four main types of renal structures

\begin{tabular}{lllll}
\hline & Glomeruli & $\begin{array}{l}\text { Blood } \\
\text { vessels } \\
(\%)\end{array}$ & Tubules & $\begin{array}{l}\text { Interstitial } \\
\text { tissue } \\
(\%)\end{array}$ \\
\hline $\begin{array}{l}\text { No clinical } \\
\text { nephropathy } \\
(n=17)\end{array}$ & $6.7 \pm 2.2$ & $8.4 \pm 2.5$ & $65.2 \pm 11.0$ & $19.7 \pm 10.0$ \\
$\begin{array}{c}\text { Severe } \\
\text { clinical } \\
\text { nephropathy } \\
(n=17)\end{array}$ & $6.9 \pm 3.0$ & $9.5 \pm 5.0$ & $50.5 \pm 7.2^{\mathrm{a}}$ & $33.1 \pm 7.2^{\mathrm{a}}$ \\
$\begin{array}{c}\text { Non-diabetic } \\
\text { subjects } \\
(n=10)\end{array}$ & $7.5 \pm 2.8$ & $7.4 \pm 3.9$ & $65.8 \pm 6.0$ & $19.4 \pm 4.9$ \\
\hline
\end{tabular}

Results are expressed as mean \pm SD. ${ }^{\text {a }} 2 p<0.001$ versus patients with no clinical nephropathy

athy than in patients without clinical nephropathy $(2 p<0.001)$. On the other hand, these patients had a significantly greater area of open capillaries and subcapsular space than patients with nephropathy $(2 p<$ 0.001 ). Much overlapping between individual cases was, however, seen in the two groups (Fig.1).

The area of fibrinoid caps was slightly increased in patients with nephropathy, and so was the area of Bowmann's capsule. The area occupied by epithelial cells was lower compared with patients without nephropathy. No correlation was found between duration of diabetes and the area of mesangial tissue or the area of open capillaries, in all the diabetic patients or in the diabetic subgroups.

Serum creatinine correlated significantly with area of mesangium ( $r=0.792,2 \alpha<0.001)$, open capillaries ( $r=0.743,2 \alpha<0.001)$, percentage of occluded glomeruli $(r=0.656,2 \alpha<0.001)$ and interstitial connective tissue $(r=0.622,2 \alpha<0.001)$. If only patients with elevated serum creatinine were evaluated, the most significant correlation was seen between mesangial area and serum creatinine $(r=0.792,2 \alpha<0.001)$.

The correlation between the mesangium and the area of open capillaries for individual cases in the three groups is presented in Figure 1. With regard to the area of open capillaries, a clear separation is seen between the two diabetic groups; nearly all patients without ne- 
Table 5. Percentage distribution of glomerular structures

\begin{tabular}{|c|c|c|c|c|c|c|c|c|c|c|c|}
\hline & $\begin{array}{l}\text { Capsule } \\
\text { of } \\
\text { Bowmann }\end{array}$ & $\begin{array}{l}\text { Capsular } \\
\text { space }\end{array}$ & $\begin{array}{l}\text { Epithelial } \\
\text { cells }\end{array}$ & $\begin{array}{l}\text { Peripheral } \\
\text { capillary } \\
\text { wall }\end{array}$ & $\begin{array}{l}\text { Capillary } \\
\text { lumen }\end{array}$ & $\begin{array}{l}\text { Open cap- } \\
\text { illaries }^{\mathrm{a}}\end{array}$ & $\begin{array}{l}\text { Mesan- } \\
\text { gium }\end{array}$ & $\begin{array}{l}\text { Subcapsu- } \\
\text { lar fibro- } \\
\text { sis }\end{array}$ & $\begin{array}{l}\text { Fibrinoid } \\
\text { cap }\end{array}$ & Hilus & $\begin{array}{l}\text { Undeter- } \\
\text { minable }\end{array}$ \\
\hline $\begin{array}{l}\text { No clinical } \\
\text { nephropathy } \\
\text { (group A) }(n=17)\end{array}$ & $9.6 \pm 2.3$ & $31.1 \pm 7.3$ & $3.0 \pm 2.3$ & $9.2 \pm 2.9$ & $20.2 \pm 5.3$ & $29.4 \pm 6.6$ & $18.4 \pm 7.3$ & $4.3 \pm 5.8$ & $0.2 \pm 0.4$ & $1.4 \pm 0.9$ & $2.3 \pm 1.0$ \\
\hline $\begin{array}{l}\text { Severe clinical } \\
\text { nephropathy } \\
\text { (group B) }(n=17)\end{array}$ & $12.9 \pm 4.0$ & $17.9 \pm 8.6$ & $1.0 \pm 0.8$ & $4.4 \pm 2.7$ & $8.1 \pm 4.4$ & $12.4 \pm 6.4$ & $32.9 \pm 9.1$ & $14.5 \pm 8.1$ & $2.2 \pm 2.2$ & $1.4 \pm 1.0$ & $4.9 \pm 2.3$ \\
\hline $\begin{array}{l}\text { Significance of } \\
\text { difference between } \\
\text { groups A and B }\end{array}$ & $<0.02$ & $<0.001$ & $<0.005$ & $<0.001$ & $<0.001$ & $<0.001$ & $<0.001$ & $<0.001$ & $<0.005$ & $<0.90$ & $<0.001$ \\
\hline $\begin{array}{l}\text { Significance of } \\
\text { difference between } \\
\text { groups A and C }\end{array}$ & $<0.10$ & $<0.50$ & $<0.20$ & $<0.20$ & $<0.05$ & $<0.025$ & $<0.001$ & $<0.05$ & $<0.20$ & $<0.30$ & $<0.001$ \\
\hline
\end{tabular}

Results are expressed as mean $\pm \mathrm{SD}$. Significance of differences between groups are expressed as $2 p$.

a Peripheral capillary wall + capillary lumen

phropathy have a greater area of open capillaries than patients with severe clinical nephropathy. In the mesangial area the separation is less clear. Only nine patients without nephropathy had mesangial areas below the lowest value among diabetics with clinical nephropathy,

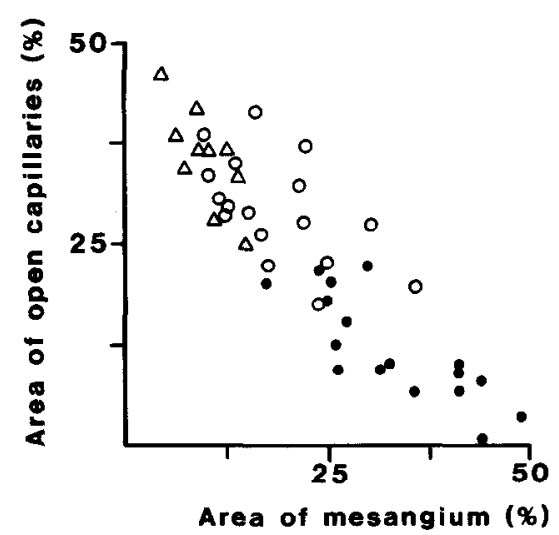

Fig. 1. Correlation between the relative area of open capillaries (peripheral capillary wall + capillary lumen) and the relative area of mesangium in non-diabetic subjects $(\Delta)$, diabetic patients without $(O)$ and with clinical nephropathy $(-\mathrm{O}) \mathrm{r}=-0.86,2 \alpha<0.001$

whereas four patients without clinical nephropathy showed values for mesangial area at about the average value of patients with nephropathy. The non-diabetic group showed low values for the mesangium and high values for the area of open capillaries with no overlapping of values for patients with clinical nephropathy.

\section{Discussion}

The development of diabetic glomerulopathy begins at the onset of diabetes [4], and the morphological alterations proceed with increasing duration of diabetes [1, $5,8]$. Therefore, duration of diabetes has to be taken into consideration, when morphological changes in dif- ferent groups of diabetic patients are compared. This demand was fulfilled in our material, when agematched patients with similar duration of diabetes were compared.

In our study, patients with severe clinical nephropathy were compared with patients without overt clinical nephropathy. Only patients with normal serum creatinine levels and normal blood pressure during the year before death were included in the group of patients without clinical nephropathy, and 24-h urine samples from all these patients were negative with Albustix on several occasions, also during the last year of life. This does not exclude a substantial increase of urinary albumin excretion rate in these patients (e.g. between 20 and $200 \mu \mathrm{g} / \mathrm{min}$ ). However, overt clinical nephropathy with persistent proteinuria of $\geqslant 0.5 \mathrm{~g}$ protein $/ 24 \mathrm{~h}$ and decreased glomerular filtration rate is very unlikely [10].

In autopsy material from kidneys of long-term Type 1 diabetic patients of juvenile onset, not only would advanced diabetic changes be expected, but in addition other heterogenous renal alterations not specifically related to diabetes but provoked by other factors (e.g. hypertension, atherosclerosis). This investigation, as well as showing classical diabetic changes, demonstrated that some alterations could be correlated with clinical nephropathy. Nodular glomerulosclerosis (Kimmelstiel-Wilson lesions) is a classical feature in diabetic glomerulopathy. Although not entirely pathognomonic for diabetes, nodular glomerulosclerosis is highly characteristic of this disease, and most authors assume Kimmelstiel-Wilson lesions to be a sign of severe clinical nephropathy $[5,6]$. Our study, however, showed that this was not the case, Kimmelstiel-Wilson lesions being present equally in diabetic patients with and without clinical nephropathy. Nodular glomerulosclerosis was seen in several diabetic patients without proteinuria in Thomson's study [1]. Nor could the exudative lesions - fibrinoid caps and capsular drops - be 
correlated with clinical nephropathy. No correlation could be demonstrated between the severity of arteriolar changes and clinical diabetic nephropathy. In spite of the highly significant difference in blood pressure between the two diabetic groups (Table 1), arteriolar hyalinosis was of the same degree in the two groups.

However, a difference was seen in interstitial connective tissue, which was found to be increased in our patients with clinical nephropathy. This is in accordance with the findings of Bader et al. [9], who analyzed renal biopsies from a mixed group of diabetic patients. These authors also demonstrated a significant correlation between the grade of fibrosis of the renal cortical interstitium and the serum-creatinine concentration. This was confirmed by the present study, but in our study the mesangial area correlated better with serum creatinine levels than with interstitial connective tissue.

The glomerular changes which seem to be most characteristic for severe clinical diabetic nephropathy, are a reduction in the area of open capillaries and an increase in the area of glomerular mesangial tissue. These alterations seem to be complementary (Fig. 1), but it is an open question whether the accumulation of mesangial tissue leads to capillary stricture, or whether a primary reduction in capillary area causes secondary glomerulosclerotic changes.

Bader et al. [9] believe that interstitial fibrosis is a primary event leading to reduced cortical blood flow and atrophy of tubules and later to impaired renal function. We cannot agree because severe interstitial fibrosis could be seen in diabetic patients without clinical nephropathy and with a normal serum creatinine. Furthermore, the area of open glomerular capillaries discriminated much better than interstitial fibrosis between diabetic patients with and without clinical nephropathy. Also, serum creatinine correlated better with mesangial area than with interstitial fibrosis. Nor do we believe that glomerulosclerosis or clinical nephropathy are secondary to arteriolohyalinosis, since no difference was apparent in the degree of hyalinosis of juxtaglomerular arterioles between the two diabetic groups.

It has been assumed that progression of the renal changes will finally lead to clinical nephropathy. This assumption was based on the observation that all insulin-dependent diabetics of juvenile onset demonstrating severe symptoms of renal disease also showed severe renal alterations [1, 6]. However, although in this study patients with clinical nephropathy had on the whole more severe glomerulosclerosis than patients without clinical nephropathy, consideration of the individual cases makes clear that advanced mesangial sclerotic changes can exist without necessarily leading to clinical nephropathy.

The glomerular change that most clearly allowed a distinction between patients with and without clinical nephropathy - rather than the mesangial increase in itself - was the area of open capillaries, which in most patients without nephropathy was in the normal range. From our results it would seem that preservation of a certain amount of open capillaries is essential to avoid the development of clinical nephropathy.

Our study cannot elucidate whether the increase of mesangial tissue or the decrease of the area of open capillaries is the cause of clinical nephropathy. It must be taken into consideration that, in our study, patients without clinical nephropathy are compared with patients demonstrating end-stage nephropathy. It cannot be excluded that the more severe morphological changes seen in patients with severe clinical diabetic nephropathy are the consequences of a new process accelerating the glomerulosclerotic process leading to nephron occlusion and declining glomerular filtration rate [10]. Morphological studies of renal tissue taken at earlier stages of clinical nephropathy are therefore urgently needed.

Acknowledgement $\mathrm{We}$ are thankful to all the pathologists in Denmark who kindly supplied us with tissue blocks from our patients. A. Eriksen and L. Bendixen are thanked for excellent histotechnical work, and $\mathbf{J}$.Olsen for typing the manuscript. Some of the data were published at INSERM Symposium No.22, Abbaye de Fontevraud, France, May 1982 [10]

\section{References}

1. Thomsen $\AA \mathrm{C}$ (1965) The kidney in diabetes mellitus. Thesis. Munksgaard, Copenhagen

2. Honey GE, Pryse-Davies J, Roberts DM (1962) A survey of nephropathy in young diabetics. Q J Med 124:473-483

3. Watkins PJ, Blainey JD, Brewer B, Fitzgerald MG, Malins JM, O'Sullivan DJ, Pinto JA (1972) The natural history of diabetic renal disease. Q J Med 164: 437-456

4. Østerby $\mathbf{J}$ (1973) Morphometric studies of the peripheral glomerular basement membrane. Diabetologia 9: 108-114

5. Gellman DD, Pirani CL, Soothill JF, Muehrcke RC, Kark RM (1959) Diabetic nephropathy: a clinical and pathologic study based on renal biopsies. Medicine (Baltimore) 38: 321-367

6. Hatch FE, Watt MF, Kramer NC, Parrish AE, Howe JS (1961) Diabetic glomerulosclerosis. Am J Med 31:216-230

7. Bader H, Meyer DS (1977) The size of the juxtaglomerular apparatus in diabetic glomerulosclerosis and its correlation with arteriolosclerosis and arterial hypertension: a morphometric light microscopic study on human renal biopsies. Clin Nephrol 8: 308-311

8. Gundersen HJG, Østerby R (1977) Glomerular size and structure in diabetes mellitus. II. Late abnormalities. Diabetologia 13: $43-48$

9. Bader R, Bader H, Grund KE, Mackensen-Haen S, Christ H, Bohle A (1980) Structure and function of the kidney in diabetic glomerulosclerosis. Correlation between morphological and functional parameters. Pathol Res Pract 167: 204-216

10. Deckert T, Parving H-H, Andersen AR, Christiansen JS, Oxenbøll B, Svendsen PAA, Telmer S, Christy M, Lauritzen T, Thomsen OF, Kreiner S, Andersen JR, Binder C, Nerup J (1982) Diabetic nephropathy. In: Eschwege $\mathrm{E}$ (ed) Advances in diabetes epidemiology. INSERM Symposium No. 22. Elsevier, Amsterdam. New York Oxford, pp 235-243

Received: 19 September 1983

and in revised form: 27 February 1984

Dr. Torsten Deckert

Steno Memorial Hospital

DK-2820 Gentofte

Denmark 